Int. J. Morphol.,

35(3):799-803, 2017.

\title{
A Novel Method for Localizing Nerve Entry Points During Spasticity Treatment
}

\author{
Un Nuevo Método para Localizar los Puntos de Entrada \\ del Nervio Durante el Tratamiento de la Espasticidad
}

Shengbo Yang ${ }^{1}$; Shuangjiang $\mathrm{Hu}^{2}$; Xufeng Tian ${ }^{2} \&$ Shuaiyu $\mathrm{Hu}^{1}$

YANG, S.; HU, S; TIAN, X. \& HU, S. A novel method for localizing nerve entry points during spasticity treatment. Int. J. Morphol., 35(3):799-803, 2017.

SUMMARY: The nerve entry points (NEPs) cannot be accurately localized for the treatment of muscle spasticity in neurolysis. The aim of this study was to develop a new method of accurately localizing nerve entry points in relation to bony landmarks. NEPs in human cadavers were coated with barium sulfate. Method 1 consisted of horizontal and longitudinal reference lines being designated based on bony landmarks, followed by radiography and measurements using picture archiving and communication system software. Method 2 involved sewing the barium sulfate-soaked suture thread into the skin to designate the horizontal and longitudinal reference lines, followed by computed tomography (CT) scanning to determine the skin surface location and puncture depth for the NEPs. Using method 1 , the bony landmarks and nerve muscular branches labeled with barium sulfate were clearly visualized by radiography. NEPs were localized using the reference lines, but the resultant points were not on the skin surface, and information was not provided regarding puncture depth. Method 2 resulted in the bony landmarks, NEPs, and reference lines being clearly visualized using CT imaging. The NEPs were successfully projected onto the skin surface and localized using reference lines that were measured along the curve of the skin. Furthermore, method 2 provided measurements of puncture depth. NEPs, including depths, can be accurately localized in cadavers using CT. Therefore, this novel method is recommended for localizing neurolysis target points.

KEY WORDS: Spasticity; Nerve entry points; Anatomy; X-ray; Localization.

\section{INTRODUCTION}

Spasticity is a common clinical manifestation of stroke, spinal cord injury, head injury, multiple sclerosis, cerebral palsy, and other nervous system diseases (Lorentzen et al., 2010). Neurolysis is a common clinical treatment for spasticity, and comprises injections of alcohol or phenol into the relevant nerve trunk or nerve entry points (NEPs); motor points). This treatment produces myelin loss, axonal degeneration, and ultimately results in local neuromuscular activity deficits (Kocabas et al., 2010; Lee \& Jang, 2012; Lam et al., 2015). However, nerve trunk injections can produce a variety of complications including sensory paralysis, thrombosis following accidental injection into local blood vessels, and even local muscle fibrosis or contracture resulting from repeated injections (Yalcin et al., 2014). The efficacy and safety of neurolysis is improved by injection into an external nerve branch rather than a nerve trunk (Kocabas et al.; Ghai et al., 2013). However, the success of the neurolysis procedure depends on accurate localization of NEPs. Currently, general anatomical descriptions of muscle shapes and nerve trunk courses, gross anatomical measurements of NEPs, and ultrasound or electrical stimulator guidance permit only rough estimations of actual NEP locations (Yoo et al., 2002; Song et al., 2014; Lam et al.). Therefore, inaccurate localization is a considerable risk and exploratory puncture is often required for confirmation of NEP locations.

Recently a combination of radiography and electrical stimulator guidance successfully localized the obturator nerve prior to an ethanol block (Viel et al., 2002). In another study, dynamic computed tomography (CT) scanning determined puncture needle positioning relative to the target nerve for thoracic and lumbar sympathetic nerve blocks (Nickel et al., 2008; Andresen et al., 2009). However, these methods are inconvenient because they require radiology equipment, result in prolonged radiation exposure, and are expensive. Magnetic resonance imaging (MRI) has also been used to identify large

${ }^{1}$ Department of Anatomy, Zunyi Medical College, Zunyi, Guizhou, People's Republic of China.

${ }^{2}$ Department of Radiology, the First Affiliated Hospital of Zunyi Medical College, Zunyi, Guizhou, People's Republic of China. 
nerve trunks, but this is expensive and time-consuming. Moreover, relatively small muscular nerve branches are difficult to identify using MRI (Torres et al., 2013; Delaney et al., 2014).

A more accurate and convenient method of NEP localization is required. Therefore, we sought to identify NEPs in adult cadavers, using radiography followed by determination of skin surface location and puncture depth, supported by measurement software. Development of this method contributes to improved NEP mapping accuracy, and will ultimately improve spasticity treatment for patients.

\section{MATERIAL AND METHOD}

Specimens and ethics. This study was conducted on the lower limbs of two formalin-fixed adult Chinese cadavers (a 50-yearold man and a 40-year-old woman). Neither participant had a history of neuromuscular disease. Cadavers were placed in supine anatomical positions, with extended hips and knees, and the muscular nerve branches of the femoral triangle were studied. This experiment was approved by the ethics committee of Zunyi Medical College, China.

Method 1: Localization of NEPs using anatomical landmarks and radiography. The femoral triangle of the left lower limb of the male cadaver was dissected to expose the muscular branches of the femoral and obturator nerves. The superficial fascia and adipose tissue were removed. Incisions were made along the origin of the adductor longus, adductor brevis, sartorius, and rectus femoris muscles to expose the underlying muscular nerve branches. Next, different types of copper wire were sutured to individual muscular nerve branches and the incisions were closed in layers. Radiographic images of the branch locations were obtained using X-rays (Siemens, Aristos VX PLUS, Germany) (Fig. 1A). The copper wire was clearly visualized on radiographic images; however, it was difficult to use the wire as a representative of nerve morphology in areas where the proximal end of the nerve branch was thick and the distal end was thin. Additionally, copper wire is soft and displacement may have occurred during tissue repositioning. Furthermore, we observed inconsistencies between the copper wire and anatomical observations of the neural course. Therefore, we discontinued using the distal end of the copper wire to localize NEPs. The copper wires were removed and barium sulfate combined with 801 glue (Shanghai Micro Spectral Chemical Technology Service Co. Ltd., Shanghai, China) was used to stain the muscular nerve branches. The barium sulfate mixture was dried using heat and incisions were closed in layers. Next, we obtained radiographs of the left thigh, and used Kwon's method (Kwon et al., 2009) to describe the mediolateral and superioinferior relationships between the NEP for each muscle and bony landmarks; a line joining the pubic tubercle and the greater trochanter of the femur was designated as the horizontal reference line $(\mathrm{H})$; a line joining the pubic tubercle and the medial epicondyle of the femur was designated as the longitudinal reference line (L) (Fig. 1B). The lengths of the $\mathrm{H}$ and $\mathrm{L}$ reference lines were measured using picture archiving and communication system (PACS) Impax6 software (AGFA Co., Düsseldorf, Germany). The distance from the intersection $\left(\mathrm{P}_{\mathrm{H}}\right)$ after the vertical NEP (i.e. the puncture point, $\mathrm{P}$ ) and the $\mathrm{H}$ line to the pubic tubercle was designated as $\mathrm{H}^{\prime}$, and the distance from the intersection $\left(\mathrm{P}_{\mathrm{L}}\right)$ through $\mathrm{P}$ of the horizontal line and the $\mathrm{L}$ line to the pubic tubercle was designated as L'. $\mathrm{H}^{\prime}$ and $\mathrm{L}^{\prime}$, as well as ratios of $\mathrm{H}^{\prime} / \mathrm{H}$ and $\mathrm{L}^{\prime} / \mathrm{L}$ were calculated and expressed as percentages. Adductor magnus muscle measurements were arbitrarily selected as an example to describe NEP localization (Fig. 1C).

Method 2: Localization of nerve entry points using anatomical landmarks and spiral CT. The femoral triangle of the right lower limb of the female cadaver was dissected. The skin and superficial fascia were treated as one layer, and the muscle surface was exposed to minimize tissue damage and provide access to all NEPs for the obturator and femoral muscular branches. Barium sulfate combined with 801 glue was used to stain the distal $0.5 \mathrm{~cm}$ of the muscular nerve branches. The barium sulfate mixture was then dried using heat and the incision was closed in layers. In order to describe the superioinferior relationship between the NEP of each muscle and bony landmarks, a suture thread immersed in barium sulfate was sewn into the skin between the femoral greater trochanter and the femoral lateral epicondyle and designated as L. In order to describe the mediolateral relationship between NEPs and bony landmarks, another suture thread immersed in barium sulfate was sewn into the skin between the femoral greater trochanter and the pubic tubercle and designated as $\mathrm{H}$ (Fig. 2A). Spiral CT scanning was conducted using a 64-row scanner (Siemens, Germany) (collimation $=64 \times 1$, slice thickness $=1 \mathrm{~mm}$, pitch $=1: 1$, current $=120 \mathrm{kV}$ with automatic $\mathrm{mA}$ adjustment, thin layers with three-dimensional image reconstruction). For each NEP, the first appearance of a point labeled by barium sulfate in the distal-to-proximal direction was located and an injection needle was inserted perpendicular to the coronal plane. CT scanning was repeated and thin slice reconstruction was used to determine whether P corresponded with the NEP (Fig. 2A). Finally, a Syngo system (Siemens, Berlin and Munich, Germany) measured the NEP of the adductor magnus muscle as an example. In transverse and coronal images, the $\mathrm{L}$ and $\mathrm{H}$ lines were measured by applying a curve measurement tool along the surface of the skin (Fig. 2B, C). The curve distance from $\mathrm{P}_{\mathrm{L}}$ of the horizontal NEP (i.e. P) and the $\mathrm{L}$ line to the greater trochanter was 


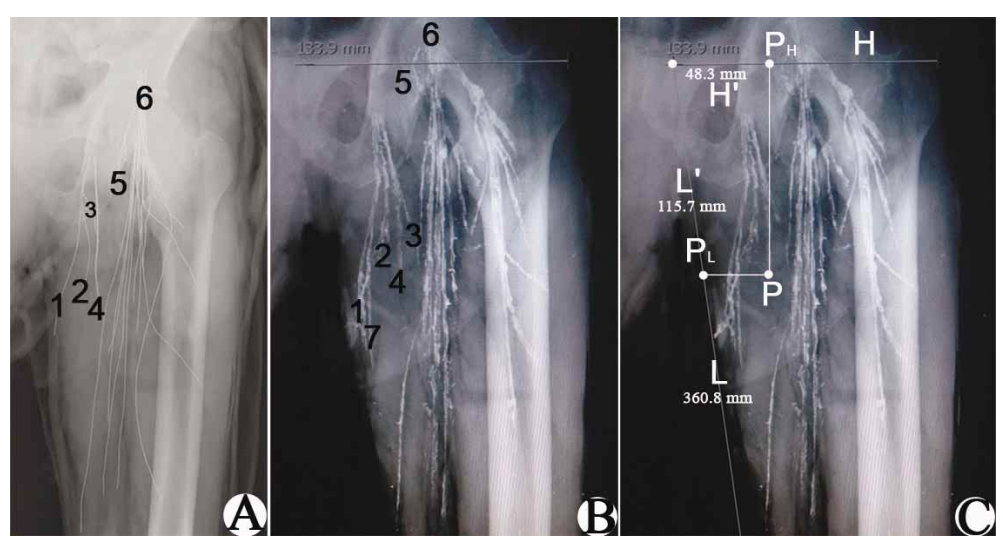

Fig. 1. Localization of nerve entry points (NEPs) with radiographic guidance. A. Radiographic image of copper bound to the muscular nerve branches. $1=$ gracilis muscle branch of the obturator nerve; 2 = adductor longus muscle branch; $3=$ adductor brevis muscle branch; $4=$ adductor magnus muscle branch; $5=$ pectineus muscle branch; 6 = femoral nerve trunk. B. Radiography of a muscular nerve branch stained with barium sulfate. $7=$ the medial femoral cutaneous branch of the obturator nerve. C. Identification of the precise NEP of the adductor magnus muscle relative to bony landmarks.

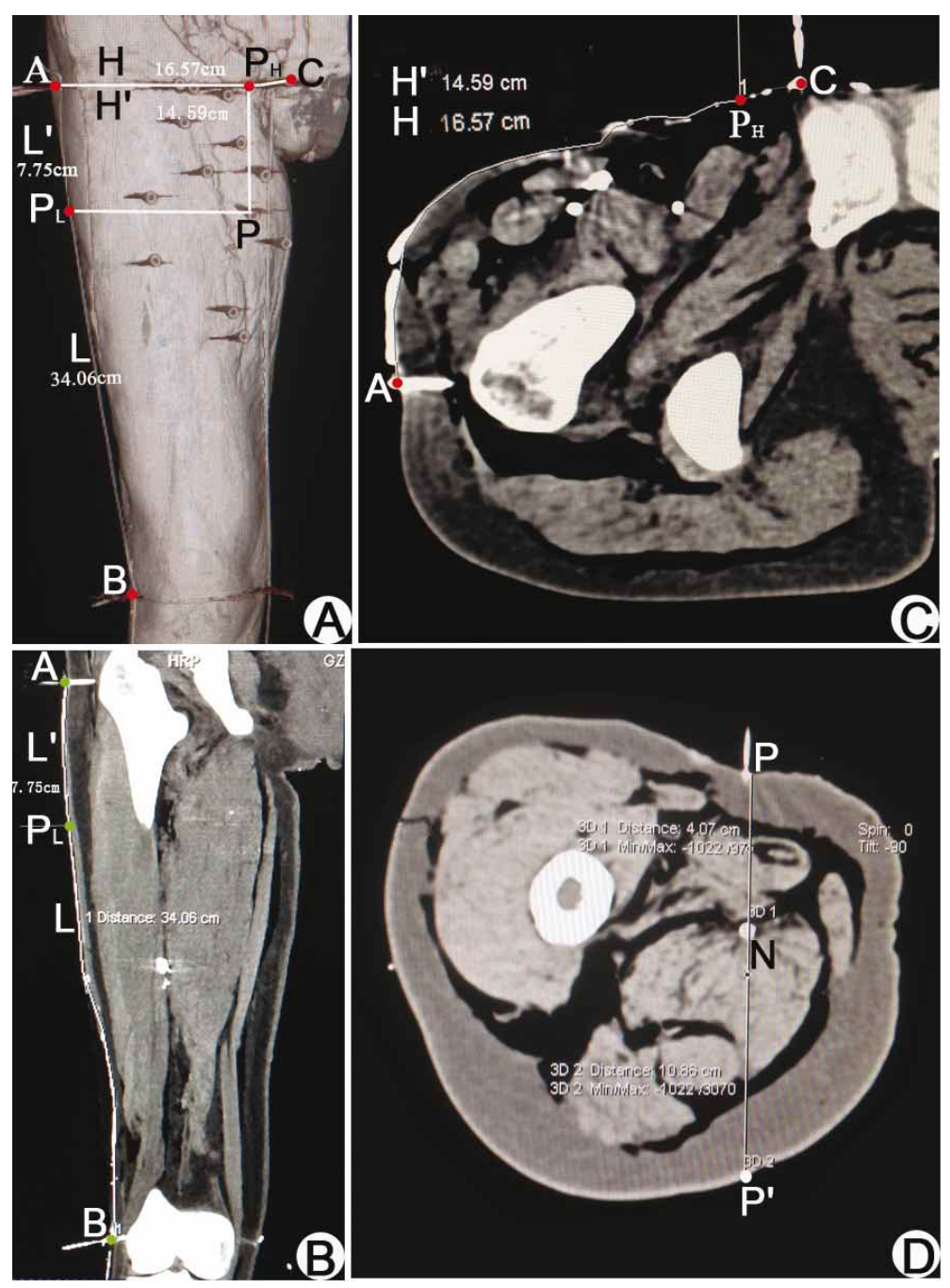

designated as L' (Fig. 2B). The curve distance from $\mathrm{P}_{\mathrm{H}}$ of the vertical NEP and the $\mathrm{H}$ line to the greater trochanter was designated as $\mathrm{H}^{\prime}$ (Fig. 2C). $\mathrm{H}^{\prime}$ and $\mathrm{L}^{\prime}$, as well as ratios of $\mathrm{H}^{\prime} / \mathrm{H}$ and $\mathrm{L}^{\prime} / \mathrm{L}$ were calculated and expressed as percentages, in order to determine $\mathrm{P}$ on the body surface. Using CT cross sections, NEPs were designated as N, P by $\mathrm{N}$ projecting to the skin of the opposite direction limb was designated as $\mathrm{P}^{\prime}$, the lengths of $\mathrm{PN}$ and PP' were measured, and the ratio of PN/PP' was calculated and expressed as a percentage in order to determine the puncture depth (Fig. 2D).

\section{RESULTS}

Method 1 included copper wires bound to nerve muscular branches being visualized using radiography. However, the imaged positions of copper wires and the anatomical observations for some nerve branches were inconsistent, such as for the adductor brevis branch (Fig. 1A). A barium sulfate alternative was then conducted, and also permitted clear radiographic imaging of muscular nerve branches. The resulting images accurately depicted the anatomy, and the nerve appearances and shapes completely corresponded with anatomical observations (Fig. 1B). Therefore, the barium sulfate method was selected as a more effective method for visualizing muscular nerve branches. The adductor magnus branch of the obturator muscular nerve branches (Fig. 1B) was selected as a location measurement example (Fig. 1C), with $\mathrm{H}^{\prime} / \mathrm{H} \times 100 \%=36.07 \%$ and $\mathrm{L}^{\prime} / \mathrm{L} \times 100 \%=32.06 \%$. Therefore, the NEP (i.e. P) was located at $36.07 \%$ lateral to the pubic

Fig. 2. Corresponding surface locations and depths of nerve entry points (NEPs) were determined by spiral computed tomography (CT). A. A three-dimensional reconstructed spiral CT image showing the relationship between the location of the NEPs and bony landmarks. $\mathrm{A}=$ greater trochanter of the femur, $\mathrm{B}=$ lateral epicondyle of the femur, $\mathrm{C}=$ pubic tubercle, $\mathrm{AB}=$ longitudinal reference line $(\mathrm{L}), \mathrm{AC}=$ horizontal reference line $(\mathrm{H}), \mathrm{P}$ $=$ puncture point for the NEP of the adductor magnus muscle, $\mathrm{AP}_{\mathrm{L}}=\mathrm{L}^{\prime}, \mathrm{AP}_{\mathrm{H}}=\mathrm{H}^{\prime}$. B. The curve lengths of $\mathrm{L}$ and $\mathrm{L}^{\prime}$ were measured on coronal images. $\mathrm{C}$. The curve lengths of $\mathrm{H}$ and $\mathrm{H}^{\prime}$ were measured on cross sectional images. D. The percentage puncture depth on a crosssectional CT image of the NEP for the adductor magnus. 
tubercle along line $\mathrm{H}$ and at $32.06 \%$ distal to the pubic tubercle along line L.

Method 2 used gross anatomy rather than exposure of the whole muscle branch of the nerve, in order to minimize tissue damage. The $\mathrm{H}, \mathrm{H}^{\prime}, \mathrm{L}$, and L' lines were located and measured along the surface of the skin using CT images. Using bony landmarks, the NEPs were also located at the skin level. The precise length can be measured during clinical applications using a measuring tape; however, the skin crease between the pubic tubercle and the roots of the thigh prohibit this strategy from being practical for measuring the $\mathrm{L}$ and $\mathrm{L}$ ' lines. Therefore, a line joining the greater trochanter and the lateral epicondyle of the femur was selected as the L line for method 2. The needles presented in Fig. 2A represent the body surface NEP puncture targets for the femoral and obturator muscular nerve branches. The NEP of the adductor magnus muscle was selected for localization measurements and identified as follows: $\mathrm{L}^{\prime} / \mathrm{L} \times 100 \%=22.75 \%$ (Fig. $2 \mathrm{~B}$ ), $\mathrm{H}^{\prime} / \mathrm{H} \times 100 \%=$ $88.05 \%$ (Fig. 2C). These values indicate that the NEP puncture target on the skin was located at $22.75 \%$ distal to the greater trochanter along line $\mathrm{L}$ and $88.05 \%$ medial to the greater trochanter along line $\mathrm{H}$.

A tape measure can be used according to method 2, in order to determine the adductor magnus NEP with method 2, by measuring the curve distances of the $\mathrm{H}$ and $\mathrm{L}$ lines to localize the appropriate surface puncture point. Using CT cross sections (Fig. 2D), we determined that $\mathrm{PN} / \mathrm{PP}^{\prime} \times 100 \%=37.47 \%$, indicating that the clinical implementation of neurolysis through $\mathrm{P}$ can be accomplished by measuring the distance of PP' with a pelvis measuring instrument, multiplying the resultant value by $37.47 \%$, and using that value as the depth of the NEP perpendicular to the coronal plane.

\section{DISCUSSION}

After central nervous system damage, unbalanced mutual restriction and interaction between alpha motor neurons and gamma motor neurons can result in weakened central motion suppression, spinal disinhibition, and motion loop excitability enhancement, which produce spasticity (increased muscle tension in the affected limb and display of the WernickeMann posture) (Hefter et al., 2012). Abnormal movements and posture greatly affect patient quality of life and also affect family members and society. Thus, strategies for more accurate localization of NEPs are urgently needed in order to improve the efficacy of spasticity treatments and reduce undesirable complications.

Several reports describe anatomical localization of
NEPs. For example, one study used a longitudinal reference line joining the pubic symphysis and the medial condyle of the femur, in order to determine the NEPs of each muscle in the adductor femoral group of an adult cadaver (Crystal et al., 2005). In another study, the medial and lateral epicondyles of the femur were used as bony landmarks and the distance to the motor branch of the gastrocnemius muscle was measured in order to determine the motor branch NEP (Yoo et al.). However, these studies described only the superioinferior relationship, not the mediolateral relationship between NEPs and bony landmarks. Another study used the distance from the pubic tubercle to the femoral medial epicondyle as a longitudinal reference line and the distance from the pubic tubercle to the greater trochanter of the femur as a horizontal reference line, but the obtained distances were based on straight lines and did not localize the NEP on the surface of the skin (Kwon et al.). Puncture depths were also not specified. Punctures are performed on the skin in clinical practice, therefore, this method is vulnerable to error.

The above-mentioned method is similar to method 1 used in the present study. We reduced errors by using PACS software, however, this method remains unfeasible for clinical use. To compensate for the issues identified by using method 1, we designed method 2 using spiral CT scanning and threedimensional image reconstruction. Method 2 had the following advantages: (1) the NEP was localized using anatomical landmarks, which minimized damage to sensory fibers in the neural trunk; (2) barium sulfate combined with 801 glue was used to stain the NEP, and was easily visualized and eluted; (3) the puncture point for the NEP was successfully localized on the skin surface using curve measurements, which are both accurate and clinically feasible; (4) CT identified the puncture depth necessary to access the NEP; (5) distances were expressed as percentages, which reduces the influence of between-patient differences.

Despite the clinical use of bony landmarks, CT guidance, and electrical stimulator guidance, it is difficult to avoid exploratory punctures. Furthermore, small branches of muscular nerves are difficult to identify using MRI, which is expensive and time-consuming. Therefore, additional autopsy studies using the recommended methods should identify NEPs and create a whole-body map. The present study validates the utility of our method 2. If the nerve of interest branches prior to entering the muscle, barium sulfate should be used to coat the branch and avoid multiple injections. If a muscle is innervated by several nerves, the NEP for the thickest nerve branch should be targeted in order to avoid multiple injections.

Limitations of the present study include that we arbitrarily selected the NEP of the adductor magnus muscle branch as an example, and we did not describe NEPs for the obturator and femoral muscle nerve branches of our two 
cadavers. Thus, more detailed studies are needed and these future studies should also utilize larger sample sizes. Finally, the present study did not objectively compare methods 1 and 2. However, we concluded that the design of method 2 is more scientifically appropriate.

\section{CONCLUSION}

NEPs and their corresponding depths can be accurately localized in cadavers using CT. We have developed an effective novel method for localization of neurolysis target points.

ACKNOWLEDGMENTS: This work was supported by the National Natural Science Foundation of China (31540031), the Provincial Natural Science Joint Foundation of Guizhou (LH-2015-7528), and the Health and Family Planning Commission of Guizhou Province (gzwjkj2015-1-044).

YANG, S.; HU, S; TIAN, X. \& HU, S. Un nuevo método para localizar los puntos de entrada del nervio durante el tratamiento de la espasticidad. Int. J. Morphol., 35(3):799-803, 2017.

RESUMEN: Los puntos de entrada de los nervios (PENs) no pueden localizarse con precisión para el tratamiento de la espasticidad muscular en la neurolisis. El objetivo de este estudio fue desarrollar un nuevo método de localización precisa de los puntos de entrada de los nervios en relación con puntos de referencia óseos. Los PENs en cadáveres humanos se recubrieron con sulfato de bario. En el método 1 se trazaron líneas de referencia horizontales y longitudinales que fueron elegidas basándose en puntos de referencia óseos, seguidos por radiografías y mediciones utilizando un software de archivo de imágenes y de sistemas de comunicación. El método 2 implicó coser hilo de sutura, impregnado con sulfato de bario, en la piel para designar las líneas de referencia horizontales y longitudinales, seguido de la realización de tomografía computarizada (TC) para determinar la ubicación en la superficie de la piel y la profundidad de punción de los PENs. Utilizando el método 1, las marcas óseas y los ramos musculares nerviosos, marcados con sulfato de bario, se visualizaron claramente mediante radiografía. Los PENs fueron localizados utilizando las líneas de referencia, sin embargo los puntos resultantes no se encontraron en la superficie de la piel, y no se proporcionó información sobre la profundidad de la punción. El método 2 dio como resultado la correcta visualización de los puntos de referencia óseos, los PENs y las líneas de referencia, utilizando imágenes de TC. Los PENs se proyectaron con éxito sobre la superficie de la piel y se localizaron usando líneas de referencia que se midieron a lo largo de la ésta. Además, el método 2 proporcionó mediciones acerca de la profundidad de punción. Los PENs, incluyendo las profundidades de punción, pueden ser localizados con exactitud en cadáveres usando TC. Por lo tanto, este nuevo método se recomienda para localizar los puntos objetivos de la neurolisis.

PALABRAS ClAVE: Espasticidad; Puntos de entrada del nervio; Anatomía.

\section{REFERENCES}

Andresen, R.; Radmer, S.; Nickel, J.; Fischer, G. \& Brinckmann, W. Ambulatory CT-assisted thoracic sympathetic block as an additional approach to treatment of complex regional pain syndromes after sport injuries. Z. Orthop. Unfall., 146(6):736-41, 2008

Crystal, R.; Malone, A. A. \& Eastwood, D. M. Motor points for neuromuscular blockade of the adductor muscle group. Clin. Orthop. Relat. Res., (437):196200, 2005.

Delaney, H.; Bencardino, J. \& Rosenberg, Z. S. Magnetic resonance neurography of the pelvis and lumbosacral plexus. Neuroimaging Clin. N. Am., 24(1):12750, 2014.

Ghai, A.; Sangwan, S. S.; Hooda, S.; Garg, N.; Kundu, Z. S. \& Gupta, T. Evaluation of interadductor approach in neurolytic blockade of obturator nerve in spastic patients. Saudi J. Anaesth., 7(4):420-6, 2013.

Hefter, H.; Jost, W. H.; Reissig, A.; Zakine, B.; Bakheit, A. M. \& Wissel, J. Classification of posture in poststroke upper limb spasticity: a potential decision tool for botulinum toxin A treatment? Int. J. Rehabil. Res., 35(3):22733, 2012.

Kocabas, H.; Salli, A.; Demir, A. H. \& Ozerbil, O. M. Comparison of phenol and alcohol neurolysis of tibial nerve motor branches to the gastrocnemius muscle for treatment of spastic foot after stroke: a randomized controlled pilot study. Eur. J. Phys. Rehabil. Med., 46(1):5-10, 2010.

Kwon, J. Y.; Kim, J. S. \& Lee, W. I. Anatomic localization of motor points of hip adductors. Am. J. Phys. Med. Rehabil., 88(4):336-41, 2009.

Lam, K.; Wong, D.; Tam, C. K.; Wah, S. H.; Myint, M. W.; Yu, T. K.; So, K. K.; Cheung, G.; Au, K. M.; Fu, M. H.; Wu, Y. M. \& Kng, C. P. Ultrasound and electrical stimulator-guided obturator nerve block with phenol in the treatment of hip adductor spasticity in long-term care patients: a randomized, triple blind, placebo controlled study. J. Am. Med. Dir. Assoc., 16(3):238-46, 2015.

Lee, D. G. \& Jang, S. H. Ultrasound guided alcohol neurolysis of musculocutaneous nerve to relieve elbow spasticity in hemiparetic stroke patients. NeuroRehabilitation, 31(4):373-7, 2012.

Lorentzen, J.; Grey, M. J.; Crone, C.; Mazevet, D.; Biering-Sørensen, F. \& Nielsen, J. B. Distinguishing active from passive components of ankle plantar flexor stiffness in stroke, spinal cord injury and multiple sclerosis. Clin. Neurophysiol., 121(11):1939-51, 2010.

Nickel, J.; Brinckmann, W. \& Andresen, R. Ambulatory, CT-assisted lumbar sympathicolysis in patients with severe peripheral artery disease: influence on peripheral blood flow and clinical outcome. Zentralbl. Chir., 133(4):349$54,2008$.

Song, D. H.; Chung, M. E.; Han, Z. A.; Kim, S. Y.; Park, H. K. \& Seo, Y. J. Anatomic localization of motor points of wrist flexors. Am. J. Phys. Med. Rehabil., 93(4):282-6, 2014.

Torres, C.; Mailley, K. \& Del Carpio O'Donovan, R. MRI of the brachial plexus: modified imaging technique leading to a better characterization of its anatomy and pathology. Neuroradiol. J., 26(6):699-719, 2013.

Viel, E. J.; Perennou, D.; Ripart, J.; Pélissier, J. \& Eledjam, J. J. Neurolytic blockade of the obturator nerve for intractable spasticity of adductor thigh muscles. Eur. J. Pain, 6(2):97-104, 2002.

Yalcin, E.; Akyuz, M.; Ilgu, O. \& Ozer, N. B. Ultrasonographically guided obturator nerve block for bilateral adductor spasticity in a paraplegic patient. Spinal Cord, 52 Suppl. 2:S24-6, 2014.

Yoo, W. K.; Chung, I. H. \& Park, C. I. Anatomic motor point localization for the treatment of gastrocnemius muscle spasticity. Yonsei Med. J., 43(5):627-30, 2002.

Corresponding author:

Prof. Shengbo Yang

Department of Anatomy

Zunyi Medical College, No. 201

Dalian Road, Zunyi City, 563000

Guizhou Province

People's Republic of China

Received: 20-01-2017

Accepted: 05-04-2017

E-mail: yangshengbo8205486@163.com 